\title{
Tonometry in corneal edema after cataract surgery: dynamic contour tonometry versus Goldmann applanation tonometry
}

This article was published in the following Dove Press journal:

Clinical Ophthalmology

2 May 2013

Number of times this article has been viewed

\author{
Anne Herr' \\ Andreas Remky ${ }^{2}$ \\ Thalia Hirsch ${ }^{\prime}$ \\ Corinna Rennings' \\ Niklas Plange' \\ 'Department of Ophthalmology, \\ RWTH Aachen University, Aachen, \\ Germany; ${ }^{2}$ Augenbelegabteilung \\ Krankenhaus Barmherzige Brueder, \\ Regensburg, Germany
}

Introduction: Intraocular pressure (IOP) determination using dynamic contour tonometry (DCT) has been considered to be independent of central corneal thickness (CCT), while Goldmann applanation tonometry (GAT) is known to be influenced by various corneal properties. In this study, IOP was measured before and 1 day after cataract surgery using GAT and DCT to investigate the possible effects of corneal edema on IOP measurements.

Methods: Thirty patients with advanced cataracts were included in a pilot study. IOP was measured using GAT and DCT before and 1 day after phacoemulsification. CCT was determined before and after surgery to quantify postsurgical corneal edema.

Results: CCT increased significantly (by $89.7 \pm 107.4 \mu \mathrm{m}, P<0.0001$ ) 1 day after surgery. No significant difference was found for IOP measurements using GAT and DCT before surgery (mean IOP GAT: $17.5 \pm 5.7 \mathrm{mmHg}$; mean IOP DCT: $17.9 \pm 6.4 \mathrm{mmHg} ; P=0.67$ ) and 1 day after surgery (mean IOP GAT: $16.1 \pm 6.6 \mathrm{mmHg}$; mean IOP DCT: $16.8 \pm 8.3 \mathrm{mmHg} ; P=0.69$ ). IOP values using GAT and DCT were significantly correlated before as well as 1 day after surgery (before surgery: $\mathrm{r}=0.82, P \leq 0.0001$; after surgery $\mathrm{r}=0.83, P<0.0001$ ). Bland-Altman plots showed a high variability in the difference in IOP measurements between methods before and 1 day after surgery.

Conclusion: GAT and DCT seem to be equally valuable in IOP determination in postsurgical central corneal edema, although large differences between both methods are present in individual patients. IOP evaluation in corneal edema remains a difficult clinical challenge.

Keywords: Goldmann applanation tonometry, dynamic contour tonometry, corneal edema, cataract surgery, intraocular pressure

\section{Introduction}

Intraocular pressure (IOP) is generally a fundamental clinical parameter in ophthalmology; in addition, it specifically concerns patients suffering from glaucoma. For this reason, it is of particular interest for clinical investigators to always question the current gold standard - Goldmann applanation tonometry (GAT) - and consider replacing it if a new, more precise method seems to be valid. This may be particularly true if tonometry is performed and the findings deviate from presumed normal ocular conditions, such as corneal edema. ${ }^{1-3}$

It is well known that the principle of applanation tonometry is influenced by the properties of the cornea, scleral rigidity, bulb dimensions, ocular muscle contractions, and arterial and venous pressure, even if measurements are accurately performed. ${ }^{1}$ In 1957, Goldmann ${ }^{2}$ was aware that applanation tonometry is subject to systemic errors due to nonstandard properties. The European Glaucoma Society outlines the most
Correspondence: Niklas Plange University Aachen, Department of Ophthalmology, Pauwelsstr 30, 52057 Aachen, Germany Email nplange@ukaachen.de submit your manuscript $\mid$ www.dovepress.com

Dovepress

http://dx.doi.org// 0.2/47/OPTH.S444/2 which permits unrestricted noncommercial use, provided the original work is properly cited. 
important clinical factors that influence GAT (ie, refractive aberration, astigmatism, tear film, corneal edema, corneal thickness, and refractive surgery). ${ }^{3}$ Several attempts have been made to correct IOP with respect to differences in structural corneal thickness, as IOP measurements using GAT are overestimated in thicker corneas. ${ }^{3}$ Schneider and $\mathrm{Grehn}^{4}$ recommend a correction of GAT measurements by $4.5 \mathrm{mmHg}$ per $100 \mu \mathrm{m}$ deviation from the mean central corneal thickness (CCT) of $551.43 \mu \mathrm{m}$. The Dresden correction formula recommends a $0.4 \mathrm{mmHg}$ correction per $10 \mu \mathrm{m}$ deviation from a mean CCT of $550 \mu \mathrm{m} .{ }^{5}$ Corneal biomechanical properties can also have a significant effect on GAT measurements. ${ }^{6}$

Dynamic contour tonometry (DCT) is a noninvasive method of determining IOP that uses a pressure-sensitive tip shaped like the surface of the central cornea. Therefore, it is intended to measure IOP with minimal deformation of the cornea to avoid dependencies in changes in corneal properties. ${ }^{7}$

In recent studies, GAT and DCT have been compared in healthy subjects with corneas of varying substantial thickness. ${ }^{8}$ IOP measurements using DCT seem to be independent of corneal thickness in cases of structurally thickened corneas, even though this is controversial. ${ }^{4,8-11}$ Other studies compared GAT and DCT measurements after refractive surgery, such as with laser in situ keratomileusis. GAT showed significantly lower IOP values postoperatively because of the thinner cornea, whereas DCT is not influenced by this procedure. ${ }^{11,12}$

In contrast to tonometry in structurally thick corneas, IOP measurements with GAT in corneal edema seem to be more complex. In routine clinical procedures, IOP may be measured as being artificially too low in edematous thickened corneas using GAT. ${ }^{3}$ Kniestedt et $\mathrm{al}^{13}$ found DCT to be closer to manometric measurements as compared to GAT, independent to the hydration status of the cornea in a study using cadaver eyes. In contrast, Oh et $\mathrm{al}^{14}$ reported that contact lens-induced mild corneal edema (mean increase of $20.6 \pm 12.9 \mu \mathrm{m}$ ) affects DCT more than GAT. The increase in CCT induced a mild IOP decrease using GAT or DCT. Interestingly, others found an increase in GAT values in mild corneal edema. ${ }^{15,16}$

The purpose of this study was to compare IOP determination by GAT and DCT in postsurgical corneal edema after cataract surgery and to compare these differences to IOP values before cataract surgery.

\section{Patients and methods}

Thirty consecutive patients with advanced cataracts who were planned for phacoemulsification were included in a pilot study (17 men, 13 women; mean age $69.7 \pm 10$ years, range 46-84 years). Patients with corneal disease affecting IOP measurements were excluded from the study. Patients with glaucoma were not excluded. Patients with refractive aberrations $\geq 8$ diopters were excluded. Adherence to the Declaration of Helsinki for research involving human subjects is confirmed. The study was approved by the RWTH Aachen University review board.

The study subjects had successfully undergone phacoemulsification under regional (peribulbar or topical) anesthesia with intracapsular lens implantation. All operations were performed by one experienced surgeon (AR). Phacoemulsification was followed by intracapsular implantation of a foldable acrylic lens (Acrilyc 44S; Acri.Tec GmbH, Hennigsdorf, Germany) in all subjects.

All examinations were performed in the same order before and 1 day after surgery by one examiner (CR). After a detailed slit lamp examination, postsurgical corneal edema was quantified using CCT determination, followed by IOP measurements (first GAT, secondly DCT). IOP measurements were performed once with each method.

CCT was determined by using a Scheimpflug camera system (Pentacam ${ }^{\circledR}$; OCULUS Optikgeräte GmbH, Wetzlar, Germany).

IOP was measured by means of GAT (Haag-Streit Immobilien AG, Köniz, Switzerland) and DCT (Pascal ${ }^{\circledR}$; SMT Swiss Microtechnology AG, Port, Switzerland) before and 1 day after cataract surgery. The tonometers were mounted on a slit lamp and the measurement was performed with the patient in an upright sitting position accordingly. Before IOP measurements were taken, the cornea was anesthetized with Proparakain-POS ${ }^{\circledR} 0.5 \%$ (Ursapharm Arzneimittel GmbH, Saarbruecken, Germany) eye drops (proxymetacain- $\mathrm{HCl}$ ). GAT measurements were always performed first to prevent operator bias related to DCT readings. DCT measurements were performed directly after GAT measurements. DCT measurements were based on at least five oscillations. A quality index (Q) score of 3 or better was accepted.

\section{Statistical analysis}

Correlations were tested using the Fisher's r-to-z test. To compare the two IOP-measurement methods (GAT and DCT), Bland-Altman plots were used. The Bland-Altman plot displays the differences between two measurement methods against the mean value of both methods. A paired $t$-test is used for comparison within the groups (eg, GAT pre- and postsurgery; GAT versus DCT within the groups). 


\section{Results}

CCT increased significantly from before surgery (545.9 $\pm 57.3 \mu \mathrm{m}$; range $401-646 \mu \mathrm{m}$ ) to 1 day after surgery (635.6 $\pm 119.6 \mu \mathrm{m}$; range $458-965 \mu \mathrm{m} ; P<0.0001)$. The mean increase in CCT from before to 1 day after surgery was $89.7 \pm 107.4 \mu \mathrm{m}$.

No significant difference was found for IOP measurements using GAT and DCT before surgery (mean IOP GAT: $17.5 \pm 5.7 \mathrm{mmHg}$; mean IOP DCT: $17.9 \pm 6.4 \mathrm{mmHg}$; $P=0.67$ ) and 1 day after surgery (mean IOP GAT: $16.1 \pm 6.6 \mathrm{mmHg}$, mean IOP DCT: $16.8 \pm 8.3 \mathrm{mmHg}$; $P=0.69)$. IOP values using GAT were significantly correlated with DCT measurements before surgery $(\mathrm{r}=0.82$; $P<0.0001)$ and 1 day after surgery $(\mathrm{r}=0.83 ; P<0.0001)$. Bland-Altman plots for a comparison between GAT and DCT measurements are presented for before surgery values (Figure 1) and for values obtained 1 day after surgery (Figure 2). The Bland-Altman-plot for 1 day after surgery IOP values was split by larger (ie, $>100 \mu \mathrm{m} ; \mathrm{n}=7$ ) and smaller (ie, $\leq 100 \mu \mathrm{m} ; \mathrm{n}=23$ ) postsurgical increases in CCT. The mean difference between IOP measurements using GAT compared to DCT before surgery was $-0.45 \pm 4.0 \mathrm{mmHg}$ (range -8.1 to $+9.0 \mathrm{mmHg}$ ). The mean difference between IOP measurements using GAT compared to DCT 1 day after surgery was $-0.75 \pm 4.3 \mathrm{mmHg}$ (range -9.0 to $+6.9 \mathrm{mmHg}$ ).

The change in IOP before to 1 day after surgery using GAT was not significantly correlated to the change in CCT ( $\mathrm{r}=-0.19 ; P=0.33)$. The change in IOP before to 1 day after surgery using DCT was not significantly correlated to the change in CCT $(r=-0.29 ; P=0.12)$.

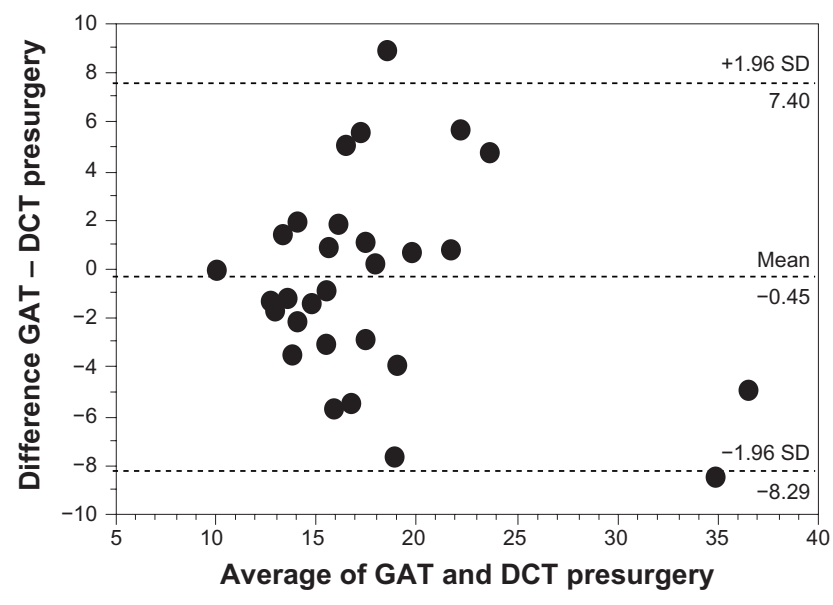

Figure I Bland-Altman plot for the comparison between GAT and DCT measurements presented for IOP values before surgery.

Abbreviations: GAT, Goldmann applanation tonometry; DCT, dynamic contour tonometry; IOP, intraocular pressure; SD, standard deviation.

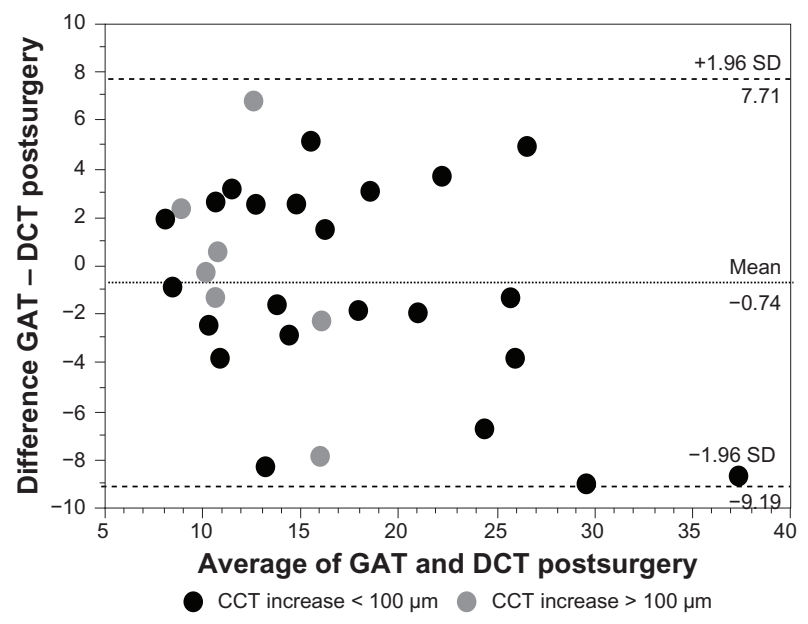

Figure 2 Bland-Altman plot for comparison between GAT and DCT measurements presented for IOP values I day after surgery.

Notes: The Bland-Altman plot is split by larger (ie, $>100 \mu \mathrm{m} ; \mathrm{n}=7$ ) and smaller (ie, $\leq 100 \mu \mathrm{m} ; \mathrm{n}=23$ ) increases in CCT.

Abbreviations: GAT, Goldmann applanation tonometry; DCT, dynamic contour tonometry; SD, standard deviation; CCT, central corneal thickness; IOP, intraocular pressure.

\section{Discussion}

Many influencing factors are known concerning IOP determination using GAT. ${ }^{1}$ Considerable increases in corneal thickness due to edema lead to false low measurements in GAT. Moses ${ }^{17}$ showed in enucleated edematous eyes that IOP determination using GAT may show differences of up to $20 \mathrm{mmHg}$ in cases of real IOP levels of $60 \mathrm{mmHg}$. Stelzer ${ }^{18}$ realized that the area of applanation by a fixed force is larger in eyes with edematous corneas than in eyes without corneal edema, which would lead to an underestimation of IOP. In contrast to corneal edema, increased structural central corneal thickness is known to increase GAT measurements, while thin corneas cause false to low measurements. Ehlers et a ${ }^{19}$ found that a CCT of $0.59 \mathrm{~mm}$ would effect a $4.7 \mathrm{mmHg}$ overestimation in the case of a real IOP of $20 \mathrm{mmHg}$. This is in accordance with the correction formulas from Schneider and Grehn, ${ }^{4}$ and the Dresden correction formula in thin corneas, while correction values differ in corneas of increased thickness. ${ }^{5}$

DCT is a method to measure IOP by using a pressuresensitive tip that is closely shaped following the corneal curvature to minimize the corneal deformation. The forces of both sides of the cornea are meant to be nearly equal during the measurement. ${ }^{7}$ DCT measurements have been shown to be independent of structural changes of the cornea such as corneal edema or CCT., ${ }^{4-13,20,21}$ However, some authors describe that DCT is not completely independent from central corneal thickness or corneal edema. ${ }^{14,22-26} \mathrm{Oh}$ et a ${ }^{14}$ induced corneal edema by having subjects wear soft contact lenses for 2 hours. This resulted in an increase in measured CCT 
of $20.6 \mu \mathrm{m}$ from baseline values of $532.6 \mu \mathrm{m}$. In their study, a nonstatistically significant decrease of GAT values (by $0.43 \pm 1.95 \mathrm{mmHg} ; P=0.17$ ) and a statistically significant decrease in DCT values (by $0.75 \pm 1.74 \mathrm{mmHg} ; P=0.01$ ) was observed. In contrast, Hamilton et $\mathrm{al}^{15}$ induced monocular corneal edema by contact lens-induced hypoxia and induced an increase of $48.3 \mu \mathrm{m}$ from baseline CCT values of $545.0 \mu \mathrm{m}$. A statistically significant increase in GAT values by $+1.5 \pm 2.8 \mathrm{mmHg}(P=0.007)$ and a decrease in DCT values $(-0.7 \pm 1.1 \mathrm{mmHg} ; P=0.001)$ was found. Kniestedt et $\mathrm{al}^{13}$ examined freshly enucleated and deepithelialized eyes in different hydration conditions and found consistently lower values in GAT than in intraocular measured IOP, while DCT showed no significant difference in IOP values obtained in different hydration conditions.

Interestingly, the effect of postsurgical corneal edema on IOP readings was not different in both methods in our study. The difference of both methods before and 1 day after surgery was similar regarding the mean difference of IOP readings, Bland-Altman-plots, or the high variability of the differences concerning individual IOP values. This seems to be the case in moderate $(\mathrm{CCT}$ increase $<100 \mu \mathrm{m})$ to pronounced corneal edema (CCT increase $>100 \mu \mathrm{m})$. Thus, the effect of corneal edema on IOP determination using either method seems to be comparable. However, only IOP measurements with both methods and manometry in an in vivo human experimental setup in corneal edema might give insights as to the fault magnitude concerning IOP determination using GAT or DCT. Secondly, our data suggest that if corneal edema has a significant effect on IOP readings using GAT, this might also be true for DCT measurements. This might be in contrast to previous studies by Hamilton et $\mathrm{al}^{15}$ and Kniestedt et al. ${ }^{13}$ For routine clinical IOP determination in corneal edema - in contrast to structural thicker corneas - our data do not support the idea that GAT be replaced by DCT.

In our experimental setup, DCT was always the first method used for IOP determination. GAT measurements might have had an influence on DCT readings related to corneal applanation, thus confounding the results. The effect of GAT measurement on corneal biomechanical properties remains speculative; this is true for patients with and without corneal edema. However, from our point of view, the effect of examiner bias might be more relevant if GAT is performed after DCT, as GAT measurement is more operator-dependent and thus might be influenced if the operator is aware of the DCT readings. Another limitation of our study is the relatively low sample size, as well as the large range of the patients' ages, which could confound the results as age-related changes in biomechanics might be relevant. In addition, intraobserver variability of IOP determination using GAT or DCT could be analyzed in more detail. However, this study was performed using a clinical setting of one measurement using either method. In routine clinical practice, IOP measurement is usually performed once.

Corneal edema affects corneal rigidity and structure. These alterations cannot be easily differentiated in patients. Therefore, IOP-measurements in corneal edema are more complex compared to structurally thickened corneas. Lau et al ${ }^{16}$ correlated the changes in corneal biomechanics with IOP readings with induced mild corneal swelling. The GAT overestimation was partially characterized by the corneal resistance factor, which represented increased corneal rigidity.

The difference between IOP values using GAT and DCT was up to $9 \mathrm{mmHg}$ for individual IOP values. Considering a single patient with corneal swelling, it is not possible to determine why GAT is higher compared to DCT and vice versa. This is also true for the estimation of the real IOP using either GAT or DCT. Therefore, clinical routine estimations of IOP in corneal edema remain complex in an individual patient.

To summarize, IOP measurements in corneal edema using GAT and DCT are significantly correlated. The change in IOP is not correlated with the extent of the corneal edema. Bland-Altman plots do not suggest that DCT is superior to GAT in estimating IOP in postsurgical corneal edema. In individual patients, IOP values may be markedly different using both methods.

\section{Disclosure}

The authors report no conflicts of interest in this work.

\section{References}

1. Whitacre MM, Stein R. Sources of error with use of Goldmann-type tonometers. Surv Ophthalmol. 1993;38(1):1-30.

2. Goldmann H. Applanation tonometry. In: Newell FW, editor. Glaucoma Transactions of the Second Conference. New York, NY: Josiah Macy Jr. Foundation; 1957:167-220.

3. Heijl A, Traverso CE, editors. Terminology and Guidelines for Glaucoma, 3rd ed. Savona, Italy: European Glaucoma Society; 2008:61-66.

4. Schneider E, Grehn F. Intraocular pressure measurement-comparison of dynamic contour tonometry and goldmann applanation tonometry. J Glaucoma. 2006;15(1):2-6.

5. Kohlhaas M, Boehm AG, Spoerl E, Pürsten A, Grein HJ, Pillunat LE. Effect of central corneal thickness, corneal curvature, and axial length on applanation tonometry. Arch Ophthalmol. 2006;124(4):471-476.

6. Liu J, Roberts CJ. Influence of corneal biomechanical properties in intraocular pressure measurement: quantitative analysis. J Cataract Refract Surg. 2005;31(1):146-155.

7. Punjabi OS, Kniestedt C, Stamper RL, Lin SC. Dynamic contour tonometry: principle and use. Clin Experiment Ophthalmol. 2006;34(9): $837-840$ 
8. Doyle A, Lachkar Y. Comparison of dynamic contour tonometry with goldmann applanation tonometry over a wide range of central corneal thickness. J Glaucoma. 2005;14(4):288-292.

9. Kaufmann C, Bachmann LM, Thiel MA. Comparison of dynamic contour tonometry with goldmann applanation tonometry. Invest Ophthalmol Vis Sci. 2004;45(9):3118-3121.

10. Ceruti P, Morbio R, Marraffa M, Marchini G. Comparison of Goldmann applanation tonometry and dynamic contour tonometry in healthy and glaucomatous eyes. Eye (Lond). 2009;23(2):262-269.

11. Kaufmann C, Bachmann LM, Thiel MA. Intraocular pressure measurements using dynamic contour tonometry after laser in situ keratomileusis. Invest Ophthalmol Vis Sci. 2003;44(9):3790-3794.

12. Siganos DS, Papastergiou GI, Moedas C. Assessment of the Pascal dynamic contour tonometer in monitoring intraocular pressure in unoperated eyes and eyes after LASIK. J Cataract Refract Surg. 2004;30(4): 746-751.

13. Kniestedt C, Nee M, Stamper RL. Accuracy of dynamic contour tonometry compared with applanation tonometry in human cadaver eyes of different hydration states. Graefes Arch Clin Exp Ophthalmol. 2005;243(4):359-366.

14. Oh JH, Yoo C, Kim YY, Kim HM, Song JS. The effect of lens-induced corneal edema on Goldmann applanation tonometry and dynamic contour tonometry. Graefes Arch Clin Exp Ophthalmol. 2009;247(3): 371-375.

15. Hamilton KE, Pye DC, Kao L, Pham N, Tran AQ. The effect of corneal edema on dynamic contour and goldmann tonometry. Optom Vis Sci. 2008;85(6):451-456

16. Lau W, Pye D. Changes in corneal biomechanics and applanation tonometry with induced corneal swelling. Invest Ophthalmol Vis Sci. 2011;52(6):3207-3214.

17. Moses RA. The Goldmann applanation tonometer. Am J Ophthalmol. 1958;46(6):865-869.
18. Stelzer R. Relationship of the corneal applanations to intraocular pressure in enucleated human eyes. Albrecht Von Graefes Arch Klin Exp Ophthalmol. 1973;189:33-41.

19. Ehlers N, Bramsen T, Sperling S. Applanation tonometry and central corneal thickness. Acta Ophthalmol (Copenh). 1975;53(1):34-43.

20. Hsu SY, Sheu MM, Hsu AH, et al. Comparisons of intraocular pressure measurements: Goldmann applanation tonometry, noncontact tonometry, Tono-Pen tonometry, and dynamic contour tonometry. Eye. 2009;23(7):1582-1588.

21. Ku JY, Danesh-Meyer HV, Craig JP, Gamble GD, McGhee CN. Comparison of intraocular pressure measured by Pascal dynamic contour tonometry and Goldmann applanation tonometry. Eye. 2006;20(2): 191-198.

22. Francis BA, Hsieh A, Lai MY, et al; for Los Angeles Latino Eye Study Group. Effects of corneal thickness, corneal curvature, and intraocular pressure level on Goldmann applanation tonometry and dynamic contour tonometry. Ophthalmology. 2007;114(1):20-26.

23. Grieshaber MC, Schoetzau A, Zawinka C, Flammer J, Orgul S. Effect of central corneal thickness on dynamic contour tonometry and Goldmann applanation tonometry in primary open-angle glaucoma. Arch Ophthalmol. 2007;125(6):740-744.

24. Lanza M, Borrelli M, De Bernardo M, Filosa ML, Rosa N. Corneal parameters and difference between Goldmann applanation tonometry and dynamic contour tonometry in normal eyes. J Glaucoma. 2008;17(6):460-464.

25. Barleon L, Hoffmann EM, Berres M, Pfeiffer N, Grus FH. Comparison of dynamic contour tonometry and Goldmann applanation tonometry in glaucoma patients and healthy subjects. Am J Ophthalmol. 2006;142(4): 583-590.

26. Milla E, Duch S, Buchacra O, Masuet C. Poor agreement between Goldmann and Pascal tonometry in eyes with extreme pachymetry. Eye (Lond). 2009;23(3):536-542.
Clinical Ophthalmology

\section{Publish your work in this journal}

Clinical Ophthalmology is an international, peer-reviewed journal covering all subspecialties within ophthalmology. Key topics include: Optometry; Visual science; Pharmacology and drug therapy in eye diseases; Basic Sciences; Primary and Secondary eye care; Patient Safety and Quality of Care Improvements. This journal is indexed on

Submit your manuscript here: http://www.dovepress.com/clinical-ophthalmology-journal

\section{Dovepress}

PubMed Central and CAS, and is the official journal of The Society of Clinical Ophthalmology (SCO). The manuscript management system is completely online and includes a very quick and fair peer-review system, which is all easy to use. Visit http://www.dovepress.com/ testimonials.php to read real quotes from published authors. 